\title{
Improvement of syrinx resolution after tonsillar cautery in pediatric patients with Chiari Type I malformation
}

\author{
Kevin M. Stanko, ${ }^{1}$ Young M. Lee, BSPH, ${ }^{1}$ Jennifer Rios, ${ }^{1}$ Adela Wu, BSc, ${ }^{1,2}$ \\ Giovanna W. Sobrinho, BS, ${ }^{1}$ Jon D. Weingart, MD, ${ }^{1}$ Eric M. Jackson, MD, ${ }^{1}$ Edward S. Ahn, MD, ${ }^{1}$ \\ Kaisorn L. Chaichana, MD, ${ }^{1}$ and George I. Jallo, MD' ${ }^{1}$ \\ 'Department of Neurosurgery, ${ }^{2}$ Johns Hopkins School of Medicine, Baltimore, Maryland
}

\begin{abstract}
OBJECTIVE Chiari Type I malformation involves caudal displacement of the cerebellar tonsils below the foramen magnum, which obstructs normal cerebrospinal fluid flow and increases intracranial pressure. Certain aspects of its surgical treatment remain controversial. A retrospective study was conducted to assess the efficacy of tonsillar cautery on syrinx resolution among pediatric Chiari patients undergoing cervicomedullary decompression.
\end{abstract}

METHODS A retrospective cohort study was performed for patients $0-18$ years of age who underwent surgical correction for Chiari Type I malformation with syrinx between 1995 and 2013. Basic demographic information was collected as well as data for preoperative symptoms, prior surgical history, perioperative characteristics, and postsurgical outcomes. Descriptive statistics were performed in addition to bivariate analyses. Candidate predictor variables were identified based on an association with tonsillar cautery with $p<0.10$. Forward stepwise likelihood ratio was used to select candidate predictors in a binary logistic regression model $\left(P_{\text {in }}=0.05, P_{\text {out }}=0.10\right)$ most strongly associated with the outcome.

RESULTS A total of 171 patients with Chiari Type I malformation with syrinx were identified, and 43 underwent tonsillar cautery. Patients who underwent tonsillar cautery had 6.11 times greater odds of improvement in their syrinx $(95 \% \mathrm{Cl}$ $2.57-14.49, p<0.001$ ). There was no effect of tonsillar cautery on increased perioperative complications as well as the need for repeat decompressions.

CONCLUSIONS Tonsillar cautery is safe and effective in the treatment of Chiari Type I malformation with syrinx and may decrease time to syrinx resolution after cervicomedullary decompression. Tonsillar cautery does not increase postoperative complications in pediatric Chiari Type I malformation patients.

http://thejns.org/doi/abs/10.3171/2015.6.PEDS14471

KEY WORDS Chiari l; syringomyelia; tonsillar cautery; dural opening; cervicomedullary decompression

$\Upsilon_{\text {the }}$ HIARI Type I malformations are characterized by caudal displacement of the cerebellar tonsils below the level of the foramen magnum or the basionopisthion line..$^{14}$ Normally, cerebellar tonsils may extend down to $3 \mathrm{~mm}$ below the level of the foramen magnum, with herniation greater than $5 \mathrm{~mm}$ considered to be abnormal. ${ }^{1}$ The herniated cerebellar tissues in Chiari I malformation can subsequently restrict CSF flow across the craniocervical junction. The true frequency of Chiari malformations in the general population remains unknown, but some studies have indicated a prevalence of $0.1 \%-$ $0.5 \% .{ }^{16}$ Furthermore, the true pathophysiology and cause of Chiari Type I malformation are not clear. While the etiology of Chiari I malformations are thought to be het- erogeneous, it is hypothesized that a "crowded" foramen magnum or basioccipital hypoplasia can lead to posterior fossa crowding and tonsillar herniation.,14

Consistent with the abnormal CSF flow present in Chiari I malformation, patients often have associated hydrocephalus and syringomyelia. Syringomyelia is defined as the development of a fluid filled cyst in the spinal chord, frequently secondary to Chiari malformation. The most common symptoms in patients include occipitocervical headaches (60\%-70\% of cases), dysesthesias, clumsiness, dysphagia, and dysarthria. ${ }^{11}$ Headaches, worsened by Valsalva maneuvers, are the most common associated symptom. Sensory and motor abnormalities, such as weakness and loss of temperature and pain sensation, are also com- 
mon. Neuroimaging, preferably by MRI, displaying 5-mm or greater displacement of the tonsils is consistent with a Chiari malformation diagnosis. ${ }^{1}$

Surgery is the first-line treatment for symptomatic Chiari malformation. Surgery is typically indicated when there is 1) presence of syrinx, 2) progressive scoliosis, and/or 3) progressive symptoms..$^{15}$ However, there is less agreement in the literature on the best surgical technique. The overarching goal of surgical treatment of Chiari malformation is the decompression of the posterior fossa, typically by way of a suboccipital craniectomy. This is typically performed in conjunction with a C-1 cervical laminectomy. There has been much discussion in the literature regarding the efficacy of bone-only decompression versus in combination with dural opening. Several procedures, however, remain controversial. One such technique is the shrinking of the tonsils with bipolar cautery. While bipolar cautery is sometimes employed in the case of severe tonsillar ectopia, many surgeons avoid the procedure for fear of damaging key structures. There is a dearth of literature on the benefits and risks of tonsillar cautery. Thus, we endeavored to assess the effects of tonsillar cautery while accounting for patient presurgical characteristics and other surgical techniques to determine postsurgical outcomes, specifically improved syrinx and need for repeat decompressions.

\section{Methods \\ Study Design}

Institutional review board approval was obtained prior to data collection. This study had a retrospective, observational cohort-study design. Participants were screened for inclusion into the study by review of all surgical notes written between January 1, 1995, and December 31, 2013. All participants who underwent surgery with a diagnosis of Chiari Type I malformation were screened for the study. Data were collected in a de-identified manner retrospectively from the patients' electronic medical charts, and data integrity was verified by random spot-checking and double data collection by 2 independent observers. The follow-up duration for each patient was up to the last Chiari-related note entered into the patient's medical chart.

\section{Tonsillar Cauterization Procedure}

Pediatric neurosurgeons performed all cervicomedullary decompressions and tonsillar cauterizations carried out in this study. The decision to cauterize the tonsils was based on the surgeon's determination of whether the flow of CSF posterior to the cervicomedullary junction was adequate after decompression. This assessment was based on intraoperative determination by gross appearance and/ or ultrasound. When the flow of CSF was deemed inadequate, tonsillar cauterization was performed. Tonsillar cauterization involved the use of low-powered bipolar cauterization to coagulate the tips of the cerebellar tonsils, including the medial aspect, taking care not to enter major blood vessels such as the posterior inferior cerebellar artery and others. Typically, tonsillar cauterization was performed in this manner until the tonsils ascended to the level of the obex or the foramen magnum.

\section{Data Collection}

We collected a variety of data on demographics, preoperative characteristics, operative techniques used, and postoperative outcomes for patients who underwent cervicomedullary decompression surgery for Chiari Type I malformation with syrinx. Demographic data collected included age at time of surgery, date of surgery, sex, and neurosurgeon. Preoperative characteristics abstracted included presence of associated syndromes, Karnofsky Performance Status (KPS), presence of syrinx, presence of hydrocephalus, and degree of tonsillar herniation on preoperative MRI. Data on presenting symptoms included the following: seizures, headache, neck pain, nausea, vomiting, diplopia, decreased hearing, vertigo, dysarthria, dysphagia, confusion, patient-reported balance problems, bladder incontinence, sensory changes (as reported by the patient), motor deficiency, sensory deficiency (as evaluated by the physician), paresthesias, language deficiency, visual deficiency, cognitive deficiency, gait deficiency, and duration of symptoms. Prior surgical history, including prior decompression, prior dural opening, prior cord untethering, and prior shunt placement, $w$ also collected. Operative procedures used during decompression were abstracted from the surgical note and included the following operative techniques: craniectomy, C-1 laminectomy, bone-only decompression, patch placement, type of patch material, dural sealant use, tonsillar cautery, dural scoring, and mesh placement. Recorded postoperative outcomes included length of hospital stay, new motor deficits, new sensory deficits, postoperative pain compared with baseline, time until improvement in pain, wound infection, reoperation for wound infection, meningocele, CSF leak, reoperation for CSF leak, new shunt placement, time to new shunt placement, repeat decompressions, time to repeat decompression, repeat MRI, improved syrinx, time to improved syrinx, and date of last follow-up. Primary outcomes assessed in this study were resolution of syrinx and need for repeat decompression. A syrinx was defined as the presence of a fluid-filled cyst in the spinal cord as evidenced by MRI. Resolution of the syrinx was defined as improvement and/or absence of this fluid-filled cyst on the postoperative MR image based on a neuroradiologist's assessment. No attempt was made to quantify the extent of syrinx.

\section{Selection of Participants}

The diagnosis of Chiari I malformation was made in conjunction with the neuroradiologist and the attending neurosurgeon. The inclusion criteria in the current study were as follows: 1 ) age $0-18$ years at the time of surgery, 2) diagnosis of Chiari Type I malformation based on neurological imaging and/or clinician reports, 3) diagnosis of syrinx, and 4) having undergone cervicomedullary decompression surgery.

\section{Statistical Analysis}

It was determined post hoc that with a total sample size of 171 patients (43 in the tonsillar cautery group vs 128 in the noncautery group), there was $80 \%$ power to detect a 25\% difference in the assessed outcomes with a Type I error rate of $\alpha=0.05$. We generated descriptive statistics 
for demographics and preoperative variables, which are reported as mean \pm SD for all continuous variables and as frequency and percentage for all categorical variables. Analysis of Kolmogorov-Smirnov statistic was performed to determine the distribution of all continuous variables. A cutoff of $\alpha=0.05$ was used for the Kolmogorov-Smirnov test to determine normality. Bivariate analysis was performed to compare the distribution of continuous and categorical variables by tonsillar cautery group. Differences in categorical variable proportions between tonsillar cautery and noncautery groups were compared using the chisquare exact Fisher's test. Comparisons between continuous variables between groups were performed using the Student t-test in the case of normally distributed variables, and the Mann-Whitney U-tests for nonnormally distributed variables. Significance was assessed at a Type I error rate of $\alpha=0.05$ for all comparisons. For each outcome measure, bivariate analyses, as described above, were performed for all demographic, preoperative, and perioperative variables. All demographics, preoperative variables, and perioperative variables found to have an association with the outcome with $p$ value of $<0.10$ were labeled as candidate predictors. These candidate predictors were assessed for collinearity using Spearman's rank correlation coefficient, and pairs of candidate predictors found to be significantly correlated according to a Type I error rate $\alpha$ $=0.05$ cutoff were identified, and the candidate predictor with the smaller absolute correlation coefficient was disqualified from multivariate analysis. Multivariate forward stepwise likelihood ratio was used to select candidate predictors in a binary logistic regression models $\left(\mathrm{P}_{\text {in }}\right.$ $\left.=0.05, \mathrm{P}_{\text {out }}=0.10\right)$ most strongly associated with the outcome (syrinx resolution or repeat decompression). All regressions were evaluated for assumptions and aptness. All statistical analyses were performed using SPSS Statistics, version 20.0.0 (IBM Corp.).

\section{Results}

\section{Demographics Characteristics}

A total of 525 patients were screened, and a total of 171 patients had syrinx associated with Chiari Type I malformation and were included in this study for analysis (Table 1). Within this group, 128 patients did not undergo tonsillar cautery while 43 did. The mean age of patients was 10.6 years (SD 4.5 years) and $108(63.2 \%)$ were female. A minority of patients, $37.4 \%$, had scoliosis diagnosed prior to cervicomedullary decompression. There was no difference between the tonsillar cautery and tonsil noncautery groups in terms of age, sex, scoliosis, and preoperative KPS. Patients who underwent tonsillar cautery were more likely to have reported nausea/vomiting $(34.9 \%$ vs $14.8 \%$, p = $0.007)$ and less likely to have reported paresthesias (11.6\% vs $28.9 \%, p=0.024$ ) as presenting symptom. There were no differences between the 2 cohorts in other presenting symptoms. Over the time period of data collection, there were distinct differences in the time periods during which the surgeons performed procedures. One surgeon in our institution (not an author of this paper) performed 86 surgeries from January 1997 to June 2012, E.A. performed 12 surgeries from March 2009 to February 2013, G.J. per- formed 43 surgeries from November 2003 to March 2013, and J.W. performed 30 surgeries from October 1998 to April 2011. There was a significant difference in the rates of tonsillar cautery between surgeons within the group. E.A. was most likely to perform tonsillar cautery $(\mathrm{n}=8$, $66.7 \%$ ), and B.C. was least likely to perform tonsillar cautery $(\mathrm{n}=8,9.3 \%)$. This could have been due to differences in patient population. Moreover, all surgeons performed tonsillar cautery. As a result, the surgeon performing the surgery was not selected as a final variable in the regression model predicting likelihood of syrinx resolution.

\section{Preoperative History}

There were no differences in the rate of prior decompression, prior dural opening, prior cord untethering, prior shunt placement, tonsil herniation $>5 \mathrm{~mm}$, degree of tonsillar herniation, or hydrocephalus between the groups (Table 1).

\section{Perioperative Characteristics}

The great majority of patients, $85.4 \%$, received a craniectomy versus a craniotomy as part of their cervicomedullary decompression surgery (Table 2). C-1 laminectomy and patch placement were other commonly used surgical techniques, with $87.7 \%$ and $79.5 \%$ of patients receiving these procedures, respectively. Less commonly used procedures included bone-only decompression, dural scoring, and mesh placement in $21.1 \%, 2.9 \%$, and $1.2 \%$ of patients, respectively. Intuitively, patients who underwent tonsillar cautery were less likely to have had bone-only decompression $(0.0 \%$ vs $28.1 \%, \mathrm{p}<0.001)$ and more likely to have had dural opening with subsequent patch placement $(100.0 \%$ vs $72.7 \%, \mathrm{p}<0.001)$, as dural opening is a prerequisite step for tonsillar cautery.

\section{Postoperative Outcomes}

Less than $15 \%$ of all patients undergoing cervicomedullary decompression experienced new motor deficit $(7.0 \%)$ or new sensory deficit $(12.3 \%)$ postoperatively (Table 3). The majority of these were due to increased severity of symptoms present preoperatively and resolved spontaneously. The majority of patients experienced improved pain after surgery $(71.9 \%)$, with improvement occurring at an average of 1.4 months after surgery. However, around one-fourth of patients with improved pain after surgery eventually relapsed to their preoperative pain levels (23.6\%), having experienced an average of 0.9 months of improved pain prior to relapse. An analysis of patients who relapsed to preoperative pain levels revealed that a greater proportion of those who relapsed to the same pain level had occipital headaches as the primary indication for surgery $(89.2 \%)$ versus those who did not relapse (61.9\%), $\mathrm{p}=0.001$ (not shown in Table 3). Additionally, patients who relapsed to the same pain levels were more likely to have had a bone-only decompression versus those who did not relapse $(37.8 \%$ vs $16.4 \%, \mathrm{p}=0.011)$. A small minority of patients experienced worsened pain (7.6\%), wound infection (8.2\%), reoperation for wound infection (1.2\%), meningocele (1.2\%), CSF leak (0.6\%), lumbar puncture $(5.6 \%)$, new shunt placement $(4.1 \%)$, or shunt revision 
TABLE 1. Demographic and clinical information for all patients*

\begin{tabular}{|c|c|c|c|c|}
\hline \multirow[b]{2}{*}{ Characteristic } & \multicolumn{3}{|c|}{ Tonsil Cauterization } & \multirow[b]{2}{*}{ p Value } \\
\hline & No $(n=128)$ & Yes $(n=43)$ & Overall $(n=171)$ & \\
\hline Age in yrs, mean (SD) & $10.5(4.4)$ & $10.9(4.7)$ & $10.6(4.5)$ & NS \\
\hline Female & $82(64.1)$ & $26(60.5)$ & $108(63.2)$ & NS \\
\hline Scoliosis & $48(37.5)$ & $16(37.2)$ & $64(37.4)$ & NS \\
\hline KPS, mean (SD) & $83.1(9.5)$ & $82.8(7.7)$ & $83.0(0.0)$ & NS \\
\hline \multicolumn{5}{|l|}{ Preoperative symptoms } \\
\hline Seizures & $5(3.9)$ & $1(2.3)$ & $6(3.5)$ & NS \\
\hline Headache & $87(68.0)$ & $29(67.4)$ & $116(67.8)$ & NS \\
\hline Neck pain & $37(28.9)$ & $9(20.9)$ & $46(26.9)$ & NS \\
\hline Nausea/vomiting & $19(14.8)$ & $15(34.9)$ & $34(19.9)$ & 0.007 \\
\hline Diplopia & $2(1.6)$ & $2(4.7)$ & $4(2.3)$ & NS \\
\hline Decreased hearing & $3(2.3)$ & $2(4.7)$ & $5(2.9)$ & NS \\
\hline Vertigo & $14(10.9)$ & $9(20.9)$ & $23(13.5)$ & NS \\
\hline Dysarthria & $4(3.1)$ & $0(0.0)$ & $4(2.3)$ & NS \\
\hline Dysphagia & $22(17.2)$ & $6(14.0)$ & $28(16.4)$ & NS \\
\hline Confusion & $1(0.8)$ & $0(0.0)$ & $1(0.6)$ & NS \\
\hline Patient-reported balance problems & $32(25.0)$ & $16(37.2)$ & $48(28.1)$ & NS \\
\hline Urinary incontinence & $11(8.6)$ & $4(9.3)$ & $15(8.8)$ & NS \\
\hline Sensory changes & $27(21.1)$ & $4(9.3)$ & $31(18.1)$ & NS \\
\hline Motor deficiency & $32(25.0)$ & $11(25.6)$ & $43(25.1)$ & NS \\
\hline Sensory deficiency & $16(12.5)$ & $2(4.7)$ & $18(10.5)$ & NS \\
\hline Paresthesias & $37(28.9)$ & $5(11.6)$ & $42(24.6)$ & 0.024 \\
\hline Language deficiency & $7(5.5)$ & $4(9.3)$ & $11(6.4)$ & NS \\
\hline Visual deficiency & $8(6.3)$ & $4(9.3)$ & $12(7.0)$ & NS \\
\hline Cognitive deficiency & $11(8.6)$ & $5(11.6)$ & $16(9.4)$ & NS \\
\hline Gait deficiency & $17(13.3)$ & $5(11.6)$ & $22(12.9)$ & NS \\
\hline Duration of symptoms in months, mean (SD) & $14.3(23.7)$ & $12.2(16.9)$ & $13.8(22.2)$ & NS \\
\hline \multicolumn{5}{|l|}{ Previous operative history } \\
\hline Decompression & $23(18.0)$ & $9(20.9)$ & $32(18.7)$ & NS \\
\hline Dural opening & $17(13.3)$ & $7(16.3)$ & $24(14.0)$ & NS \\
\hline Cord untethering & $6(4.7)$ & $0(0.0)$ & $6(3.5)$ & NS \\
\hline Shunt placement & $21(16.4)$ & $4(9.3)$ & $25(14.6)$ & NS \\
\hline \multicolumn{5}{|l|}{ Complications of Chiari Type I malformation } \\
\hline Tonsil herniation $>5 \mathrm{~mm}$ & $80(62.5)$ & $32(74.4)$ & $112(65.5)$ & NS \\
\hline Tonsil herniation in mm, mean (SD) & $12.4(5.2)$ & $13.1(3.5)$ & $12.6(4.7)$ & NS \\
\hline Hydrocephalus & $4(3.1)$ & $2(4.7)$ & $6(3.5)$ & NS \\
\hline
\end{tabular}

(4.1\%). Two patients (1.2\%) underwent a syringe-terminus shunt after unsuccessful syrinx resolution postdecompression; neither received tonsillar cautery. No one required a reoperation for CSF leak or had a confirmed case of chemical meningitis after lumbar puncture. There was no significant difference between groups, tonsillar cautery or no tonsillar cautery, for the variables above. Patients who received tonsillar cautery were, however, significantly less likely to have a repeat decompression $(7.0 \%$ vs $21.9 \%, \mathrm{p}=$ $0.038)$ and more likely to have improved syrinx (81.4\% vs $43.8 \%, \mathrm{p}<0.001)$. Additionally, patients with tonsillar cau- tery took 8.0 months (SD 11.0 months) to have improved syrinx compared with 13.1 months (SD 12.2 months) in patients without tonsillar cautery, $\mathrm{p}=0.003$.

\section{Predictors of Improved Syrinx}

A total of 171 patients with Chiari Type I malformation associated with a syrinx who underwent cervicomedullary decompression with or without tonsillar cautery were included into the stepwise linear regression predicting syrinx improvement (Table 4). The final stepwise forward regression selected KPS and tonsillar cautery for model 
TABLE 2. Operative characteristics for all patients*

\begin{tabular}{lcccc}
\hline & \multicolumn{3}{c}{ Tonsil Cauterization } & \\
\cline { 2 - 4 } \multicolumn{1}{c}{ Characteristic } & No & Yes & Overall & $p$ \\
$(n=128)$ & $(n=43)$ & $(n=171)$ & Value $\dagger$ \\
\hline Craniectomy & $111(86.7)$ & $35(81.4)$ & $146(85.4)$ & NS \\
\hline C-1 laminectomy & $114(89.1)$ & $36(83.7)$ & $150(87.7)$ & NS \\
\hline $\begin{array}{l}\text { Bone-only decompres- } \\
\text { sion }\end{array}$ & $36(28.1)$ & $0(0.0)$ & $36(21.1)$ & $<0.001$ \\
\hline Patch placement & $93(72.7)$ & $43(100.0)$ & $136(79.5)$ & $<0.001$ \\
\hline Dural scoring & $5(3.9)$ & $0(0.0)$ & $5(2.9)$ & NS \\
\hline Mesh placement & $1(0.8)$ & $1(2.3)$ & $2(1.2)$ & NS \\
\hline * Values are $n$ (\%). & & & \\
+ Bold text indicates statistical significance. & & &
\end{tabular}

entry. A higher preoperative KPS score predicted a greater odds of improved syrinx (OR 1.05, 95\% CI 1.01-1.10, $\mathrm{p}=0.015$ ). Moreover, the utilization of tonsillar cautery independently predicted an approximate sixfold increase in the likelihood of improved syrinx (OR 6.11, 95\% CI $2.57-14.49, \mathrm{p}<0.001)$. The overall model was significant $\left(\chi^{2}=26.41, \mathrm{df}=2, \mathrm{p}<0.001\right)$. Figure 1 displays the Kaplan-Meier curve assessing the time to syrinx resolution. Patients who underwent tonsillar cautery had a signifi-
TABLE 4. Final stepwise logistic regression model $\left(P_{\text {in }}=0.05\right.$, $P_{\text {out }}=0.10$ ) assessing predictors of postoperative outcomes after Chiari Type I malformation decompression surgery

\begin{tabular}{lcrr}
\hline $\begin{array}{c}\text { Dependent and } \\
\text { Independent Variables }\end{array}$ & $\operatorname{Exp}(\beta), 95 \% \mathrm{Cl}$ & Wald & p Value* \\
\hline Improved syrinx $\dagger$ & & & \\
\hline KPS & $1.05(1.01-1.10)$ & 5.86 & $\mathbf{0 . 0 1 5}$ \\
\hline Tonsil cautery & $6.11(2.57-14.49)$ & 16.82 & $<\mathbf{0 . 0 0 1}$ \\
\hline Repeat decompression $\dagger$ & & & \\
\hline Bone-only decompression & $3.67(1.58-8.63)$ & 9.18 & $\mathbf{0 . 0 0 2}$ \\
\hline * Bold text indicates statistical significance. & & \\
† Dependent variables. & & &
\end{tabular}

cantly shorter median time to syrinx improvement compared with those without tonsillar cautery ( 4.7 months vs 39.0 months, $\mathrm{p}<0.001)$. MR images obtained in patients with (Fig. 2) and without (Fig. 3) tonsillar cautery were collected prior to surgery as well as postsurgery. Figures 2 and 3 are representative images of syrinx resolution with tonsillar cautery and lack of syrinx resolution without it. There was no association between syrinx resolution and increased experience of the individual surgeons. Surgeries were divided into those that occurred before the median

TABLE 3. Postoperative outcomes for all patients*

\begin{tabular}{|c|c|c|c|c|}
\hline \multirow[b]{2}{*}{ Characteristic } & \multicolumn{3}{|c|}{ Tonsil Cauterization } & \multirow[b]{2}{*}{ p Value } \\
\hline & No $(n=128)$ & Yes $(n=43)$ & Overall $(n=171)$ & \\
\hline New motor deficit & $12(9.4)$ & $0(0.0)$ & $12(7.0)$ & 0.039 \\
\hline New sensory deficit & $18(14.1)$ & $3(7.0)$ & $21(12.3)$ & NS \\
\hline Experienced improved pain & $94(73.4)$ & $29(67.4)$ & $123(71.9)$ & NS \\
\hline Months to improved pain, mean (SD) & $1.3(3.5)$ & $1.7(2.7)$ & $1.4(3.3)$ & NS \\
\hline Relapsed to preoperative pain level & $27(28.7)$ & $2(6.9)$ & $29(23.6)$ & 0.022 \\
\hline Months of improved pain in pts w/ relapse, mean (SD) & $0.6(1.2)$ & $4.6(6.3)$ & $0.9(1.9)$ & NS \\
\hline Experienced worsened pain & $11(8.6)$ & $2(4.7)$ & $13(7.6)$ & NS \\
\hline Wound infection & $8(6.3)$ & $6(14.0)$ & $14(8.2)$ & NS \\
\hline Reoperation for wound infection & $2(1.6)$ & $0(0.0)$ & $2(1.2)$ & NS \\
\hline Meningocele & $0(0.0)$ & $2(4.7)$ & $2(1.2)$ & NS \\
\hline CSF leak & $1(0.8)$ & $0(0.0)$ & $1(0.6)$ & NS \\
\hline Lumbar puncture & $4(3.3)$ & $5(11.9)$ & $9(5.6)$ & NS \\
\hline Confirmed chemical meningitis & $0(0.0)$ & $0(0.0)$ & $0(0.0)$ & NS \\
\hline Reoperation for CSF leak & $0(0.0)$ & $0(0.0)$ & $0(0.0)$ & NS \\
\hline New shunt placement & $7(5.5)$ & $0(0.0)$ & $7(4.1)$ & NS \\
\hline Shunt revision & $7(5.5)$ & $0(0.0)$ & $7(4.1)$ & NS \\
\hline Repeat decompression & $28(21.9)$ & $3(7.0)$ & $31(18.1)$ & 0.038 \\
\hline Months to redo decompression, mean (SD) & $40.2(43.9)$ & $20.2(23.2)$ & $38.3(42.5)$ & NS \\
\hline Repeat MRI & $114(89.1)$ & $40(93.0)$ & $154(90.1)$ & NS \\
\hline Hospital stay in days, mean (SD) & $4.9(5.3)$ & $4.5(2.8)$ & $4.8(4.9)$ & NS \\
\hline Improved syrinx & $56(43.8)$ & $35(81.4)$ & $91(53.2)$ & $<0.001$ \\
\hline Months to improved syrinx, mean (SD) & $13.1(12.2)$ & $8.0(11.0)$ & $11.1(11.9)$ & 0.003 \\
\hline
\end{tabular}




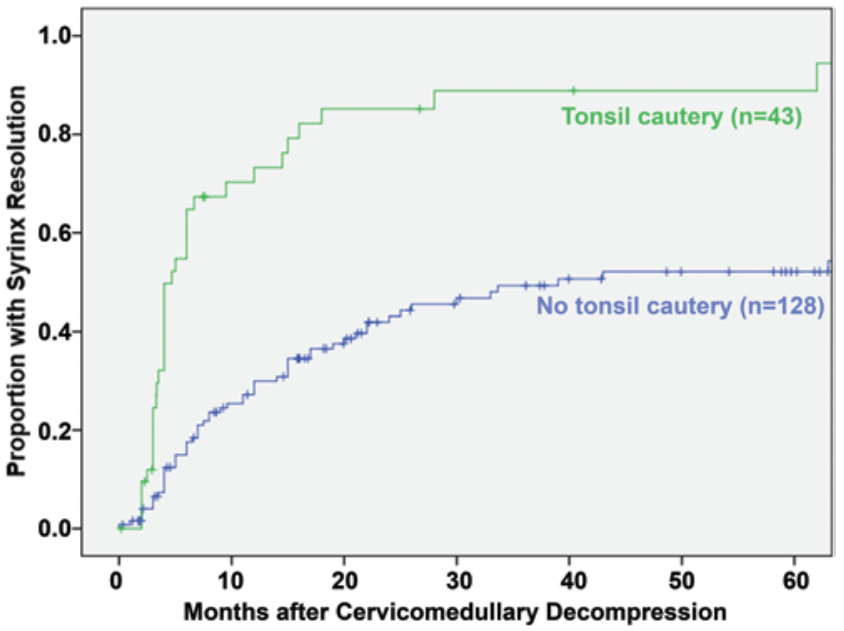

FIG. 1. Kaplan-Meier curve showing time to syrinx resolution postoperatively in patient with and without tonsil cautery. Figure is available in color online only.

date (April 2007) and those that occurred after the median date. While tonsillar cautery was more likely to have been performed after the median date $(34.9 \%)$ versus before the median date $(15.3 \%), \mathrm{p}=0.005$, there was no association between the likelihood of syringomyelia resolution and the surgery date category $(\mathrm{p}=0.445)$.

\section{Predictors of Time to Syrinx Improvement}

Ninety-three patients with syrinx underwent cervicomedullary decompression, experienced subsequent syrinx improvement, and were included into a forward stepwise linear regression predicting time to syrinx improvement (Table 5). The time to syrinx improvement was defined by the earliest MR image showing resolution of syrinx, which was not based upon a standard protocol for the timing of postoperative MRI. Typically, MR images were obtained within 3-6 months after surgery. If there was no improvement, imaging was repeated 3-4 months after the first postoperative scan. If there was improvement, MRI was spaced

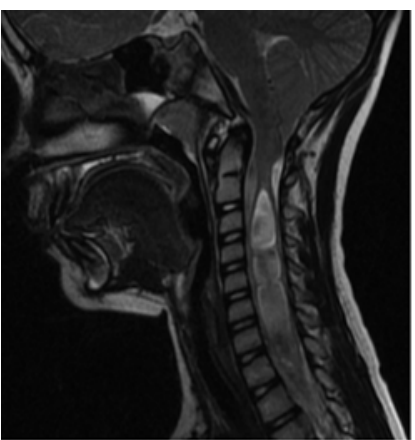

Prior to Surgery

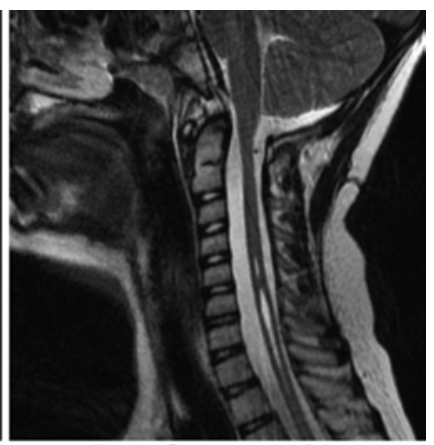

Post Surgery with Tonsillar Cautery
FIG. 2. T2-weighted MR images without contrast obtained from a pediatric patient with Chiari Type I malformation with associated syrinx who received tonsillar cauterization when undergoing cervicomedullary decompression. Left: Image showing the syrinx prior to surgery. Right: Image obtained after surgery showing significant syrinx resolution.

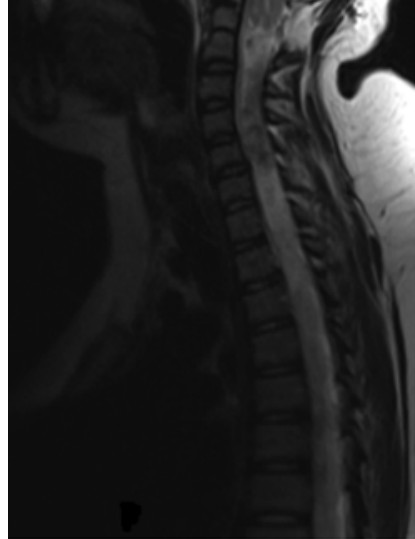

Prior to Surgery

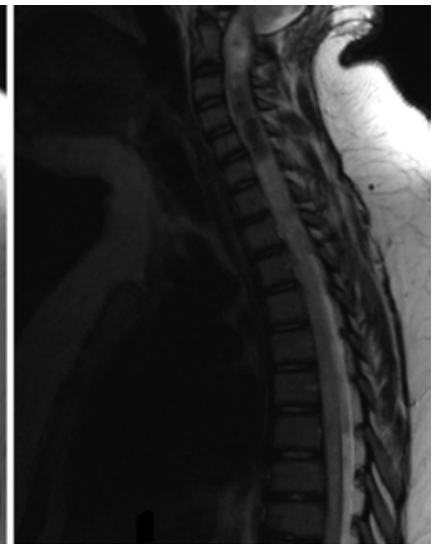

Post Surgery Without Tonsillar Cautery
FIG. 3. T2-weighted MR images without contrast obtained from a pediatric patient with Chiari Type I malformation with associated syrinx who did not receive tonsillar cauterization when undergoing cervicomedullary decompression. Left: Image showing the syrinx prior to surgery. Right: Image obtain after surgery showing no significant syrinx resolution.

out at 6- to 12-month intervals. Additionally, patients underwent repeat imaging for any worsened symptoms. The final stepwise forward regression selected age, presence of preoperative sensory changes, and history of prior decompression as predictors of time to syrinx improvement. Older age was associated with decreased time to syrinx improvement, with each year of increasing age independently associated with earlier improvement by 1.00 month (95\% CI -1.54 to $0.46, p<0.001)$. The presence of sensory changes predicted an increase in the time to syrinx improvement of 11.81 months (95\% CI 6.09-17.53, p < 0.001). Likewise, patients with a prior decompression were more likely to have an increased time to syrinx improvement $(\beta=7.33,95 \%$ CI $0.41-14.25, \mathrm{p}=0.038$ ). Overall, the final model consisting of these 5 variables, along with the intercept, explained a significant proportion of variance in the time to syrinx improvement, $\mathrm{R}^{2}=0.253, \mathrm{~F}(5,84)=5.698, \mathrm{p}<0.001$.

\section{Predictors of Repeat Decompression}

All patients $(\mathrm{n}=171)$ with Chiari Type I malformation and syrinx who underwent cervicomedullary decompres-

TABLE 5. Final stepwise linear regression model $\left(P_{i n}=0.05\right.$, $P_{\text {out }}=0.10$ ) assessing predictors of time to improvement of syrinx after Chiari Type I malformation decompression surgery

\begin{tabular}{lcrrr}
\hline $\begin{array}{c}\text { Dependent and } \\
\text { Independent Variables }\end{array}$ & $\beta, 95 \% \mathrm{Cl}$ & $\mathrm{t}$ & $\begin{array}{c}\mathrm{p} \\
\text { Value }^{*}\end{array}$ \\
\hline Time to syrinx improvement & & & \\
\hline Age & $-1.00(-1.54$ to -0.46$)$ & -3.69 & $<0.001$ \\
\hline Sensory changes & $11.81(6.09-17.53)$ & 4.10 & $<0.001$ \\
\hline Prior decompression & $7.33(0.41-14.25)$ & 2.11 & $\mathbf{0 . 0 3 8}$ \\
\hline
\end{tabular}

* Bold text indicates statistical significance.

$\dagger$ Dependent variable. 
sion were included into a forward stepwise logistic regression predicting repeat decompression (Table 4). The final stepwise forward regression selected the bone-only decompression as an independent predictor of need for repeat decompression. The use of bone-only decompression independently predicted an increased need for repeat decompression (OR 3.67, 95\% CI 1.58-8.53, $\mathrm{p}=0.002$ ). The overall model was significant in predicting repeat decompression $\left(\chi^{2}=8.77, \mathrm{df}=1, \mathrm{p}=0.003\right)$.

\section{Discussion}

In this study, we explored the effects of cauterization of herniated cerebellar tonsils in the case of a Chiari Type I malformation surgical correction. We demonstrated that cauterization of the tonsils during cervicomedullary decompression is independently associated with increased rates of improved syrinx but not independently associated with the need for repeat decompression surgery nor time to syrinx improvement.

\section{Tonsillar Cautery Independently Predicts Syrinx Improvement}

Specifically, patients who had Chiari malformation with associated syrinx and underwent tonsil cauterization as part of their cervicomedullary decompression had a sixfold increased odds of syrinx improvement (OR 6.11, 95\% CI 2.57-14.49, p < 0.001) (Table 4). In addition, the presurgical KPS score of the patient independently predicted syrinx improvement after a Chiari I decompression surgery. Patients had 1.05 times greater odds of experiencing syrinx improvement with every pointwise gain in KPS score (OR 1.05, 95\% CI 1.01-1.10). A previous study of surgical prognosis in hindbrain-related syringomyelia, based on 31 patients, found that no patients who received bipolar tonsillar cautery experienced clinical improvement and, in fact, showed a trend toward deteriorated outcome with tonsillar cautery. ${ }^{2}$ Our finding of improved outcome with tonsillar cautery was not concordant with this previous study. However, we did conduct our study on a larger sample of patients with syrinx $(n=171)$, controlling for other variables known to affect outcome. Not only did tonsil cauterization improve outcome, it did not increase the likelihood of developing new motor or sensory postsurgical deficits (Table 3). In fact, it was associated with a decreased rate of new motor deficits after surgery $(0.0 \%$ vs $9.4 \%, p=0.039$ ). Although there was no association between the rate of improved pain after surgery and tonsil cautery, patients who underwent tonsil cautery and did experience improved pain afterward were less likely to relapse to previous pain levels during our follow-up period $(6.9 \%$ vs $28.7 \%, \mathrm{p}=0.022)$. There was also no difference in rates of wound infection, CSF leaks, or shunt placements (Table 3 ). Thus, the benefits of tonsillar cautery are reaped with little to no added risk of complications.

\section{Tonsillar Cautery and Repeat Decompressions}

Upon bivariate analysis, we observed that patients who underwent tonsillar cautery had fewer repeat decompressions as compared with patients who did not undergo the cauterization procedure (Table 3). Krishna et al. studied 47 adult patients with Chiari Type I malformations who underwent bone-only decompression and found that posterior bone-only decompression resulted in long-term overall symptom improvement in most patients, but as many as one-third of patients required reoperation. ${ }^{9}$ A similarly sized study of pediatric patients undergoing posterior fossa decompression with dural opening and subsequent allogeneic duraplasty found that $89 \%$ experienced early improvement in their signs and symptoms, with a $4 \%$ repeat decompression rate. ${ }^{4}$ Another study of 82 adult patients by Yilmaz et al. reported that in cases where Chiari Type I malformation involved Grade 3 cerebellar tonsillar descent (tonsils descend over C-1 arch), dural opening with duraplasty resulted in significantly greater resolution of syrinx and clinical improvement. ${ }^{17}$ Based on this knowledge, we hypothesized that bone-only decompression, which precludes tonsillar cautery, may be responsible for the bivariate association of tonsillar cautery with decreased number of repeat decompressions. In our multivariate logistic linear regression to control for possible confounders, we found that bone-only decompression independently predicted an increase in the need for repeat decompression. In predicting the need for repeat decompression, the odds ratio for bone-only decompression was 3.67 (95\% CI 1.58$8.53, \mathrm{p}=0.002)$. Controlled for bone-only decompression, tonsillar cautery had no effect on repeat decompressions. Thus, tonsillar cautery was not independently responsible for decreased need for repeat decompressions.

\section{Controversy Surrounding Tonsillar Cautery}

There is a lack of consensus among neurosurgeons on the optimal surgical techniques to best improve patient outcome after cervicomedullary decompression for Chiari Type I malformation. ${ }^{15}$ This study is the first of its size (n $>150$ ) that provides clinically relevant, empirical evidence that tonsillar cautery is safe and can offer effective improvement of syrinx in patients undergoing posterior fossa decompression surgery for a Chiari malformation with associated syringomyelia. Cerebellar tonsil cauterization not only increases the likelihood of syrinx improvement in patients but, importantly, does not increase the incidence of new sensory or motor deficits postoperatively. Additionally, we found that dural opening and subsequent patch placement decreases rates of repeat decompression, consistent with smaller studies in the literature.9,17 Both of these surgical techniques remain controversial among neurosurgeons, and there is a dearth of large studies exploring the technique, especially tonsillar cautery.

\section{Added Benefit of Tonsillar Cautery}

Our study suggests that tonsillar cautery may provide an extra benefit with regard to resolution of syrinx versus bone-only decompression alone or in combination with dural opening. One previous study retrospectively examined 22 adult patients, concluding that selective reposition, reduction, or resection (triple " $R$ " tonsillar technique) of herniated cerebellar tonsils may improve symptoms in Chiari Type I malformation, even without bony decompression. ${ }^{5}$ Similar improvements in syrinx without need for decompression were exhibited in 15 infantile cases of Chiari Type I malformation with tonsillar reduction via 
a combination of resection and cauterization..$^{10}$ Seven of 8 patients who underwent tonsillar resection in combination with posterior fossa decompression in an older study experienced "very good" clinical outcome. ${ }^{8}$ Oldfield et al. proposed 20 years ago that in patients with Chiari Type I malformation, each systolic pressure wave in the spinal cord may cause the tonsils to push inferiorly, causing elevated pressures in the spinal cord that force CSF into the central canal along perivascular and interstitial spaces, leading to syringomyelia. ${ }^{12}$ Our evidence, in combination with the fact that no specific neurological function has been attributed to the cerebellar tonsils, ${ }^{6,13}$ suggests that tonsillar cautery may be an attractive surgical technique, in combination with posterior fossa decompression.

\section{Limitations}

Our study suffers from several limitations that must be taken into account when interpreting the results. First, the study was retrospective in nature, and although we attempted to collect data on possible confounding variables, the presence of "hidden" confounders cannot be excluded, as this was not a randomized controlled study. Second, although we did determine tonsillar herniation degree dichotomously based on physician report, we were unable to quantify the exact degree of herniation in every case. Third, this study relied on radiology reports by neuroradiologists and no attempt was made at quantifying the size of syrinx pre- and postoperatively. Lastly, as this was a chart review from patient medical records, our outcomes were primarily determined by analyzing the clinical assessments of physicians. Thus, we were unable to assess the outcomes determined most recently to be valid and responsive, such as Neck Disability Index, SF-12 (12-Item Short Form Health Survey), and EQ-5D. ${ }^{7}$ Nevertheless, we believe this study adds to our knowledge of surgical techniques for Chiari Type I malformation.

\section{Conclusions}

In conclusion, tonsillar cautery is safe and effective in the treatment of Chiari Type I patients with syrinx and may decrease the time to resolution of syrinx. It was not associated with increased risk of postoperative complications.

\section{References}

1. Aboulezz AO, Sartor K, Geyer CA, Gado MH: Position of cerebellar tonsils in the normal population and in patients with Chiari malformation: a quantitative approach with MR imaging. J Comput Assist Tomogr 9:1033-1036, 1985

2. Asgari S, Engelhorn T, Bschor M, Sandalcioglu IE, Stolke D: Surgical prognosis in hindbrain related syringomyelia. Acta Neurol Scand 107:12-21, 2003

3. Fernandes YB, Ramina R, Campos-Herrera CR, Borges G: Evolutionary hypothesis for Chiari type I malformation. Med Hypotheses 81:715-719, 2013

4. Foreman P, Safavi-Abbasi S, Talley MC, Boeckman L, Mapstone TB: Perioperative outcomes and complications associated with allogeneic duraplasty for the management of Chiari malformations Type I in 48 pediatric patients. J Neurosurg Pediatr 10:142-149, 2012

5. Galarza M, Gazzeri R, Alfieri A, Martínez-Lage JF: “Triple
R" tonsillar technique for the management of adult Chiari I malformation: surgical note. Acta Neurochir (Wien) 155:1195-1201, 2013

6. Galarza M, Sood S, Ham S: Relevance of surgical strategies for the management of pediatric Chiari type I malformation. Childs Nerv Syst 23:691-696, 2007

7. Godil SS, Parker SL, Zuckerman SL, Mendenhall SK, McGirt MJ: Accurately measuring outcomes after surgery for adult Chiari I malformation: determining the most valid and responsive instruments. Neurosurgery 72:820-827, 2013

8. Guyotat J, Bret P, Jouanneau E, Ricci AC, Lapras C: Syringomyelia associated with type I Chiari malformation. A 21-year retrospective study on 75 cases treated by foramen magnum decompression with a special emphasis on the value of tonsils resection. Acta Neurochir (Wien) 140:745-754, 1998

9. Krishna V, McLawhorn M, Kosnik-Infinger L, Patel S: High long-term symptomatic recurrence rates after Chiari-1 decompression without dural opening: a single center experience. Clin Neurol Neurosurg 118:53-58, 2014

10. Lazareff JA, Galarza M, Gravori T, Spinks TJ: Tonsillectomy without craniectomy for the management of infantile Chiari I malformation. J Neurosurg 97:1018-1022, 2002

11. Nohria V, Oakes WJ: Chiari I malformation: a review of 43 patients. Pediatr Neurosurg 16:222-227, 1990-1991

12. Oldfield EH, Muraszko K, Shawker TH, Patronas NJ: Pathophysiology of syringomyelia associated with Chiari I malformation of the cerebellar tonsils. Implications for diagnosis and treatment. J Neurosurg 80:3-15, 1994

13. Pueyrredon F, Spaho N, Arroyave I, Vinters H, Lazareff J: Histological findings in cerebellar tonsils of patients with Chiari type I malformation. Childs Nerv Syst 23:427-429, 2007

14. Schijman E: History, anatomic forms, and pathogenesis of Chiari I malformations. Childs Nerv Syst 20:323-328, 2004

15. Schijman E, Steinbok P: International survey on the management of Chiari I malformation and syringomyelia. Childs Nerv Syst 20:341-348, 2004

16. Speer MC, Enterline DS, Mehltretter L, Hammock P, Joseph J, Dickerson M, et al: Review article: Chiari Type I malformation with or without syringomyelia: prevalence and genetics. J Genet Couns 12:297-311, 2003

17. Yilmaz A, Kanat A, Musluman AM, Çolak I, Terzi Y, Kayacı $\mathrm{S}$, et al: When is duraplasty required in the surgical treatment of Chiari malformation type I based on tonsillar descending grading scale? World Neurosurg 75:307-313, 2011

\section{Disclosure}

The authors report no conflict of interest concerning the materials or methods used in this study or the findings specified in this paper.

\section{Author Contributions}

Conception and design: Chaichana. Acquisition of data: Chaichana, Stanko, Rios, Sobrinho. Analysis and interpretation of data: Chaichana, Stanko. Drafting the article: Stanko, Rios, Wu. Critically revising the article: Chaichana, Stanko, Rios, Wu, Sobrinho, Jackson, Jallo. Reviewed submitted version of manuscript: all authors. Approved the final version of the manuscript on behalf of all authors: Chaichana. Statistical analysis: Chaichana, Stanko. Administrative/technical/material support: Chaichana. Study supervision: Chaichana.

\section{Correspondence}

Kaisorn L. Chaichana, Department of Neurosurgery, Johns Hopkins School of Medicine, 1800 Orleans St., Zayed 6007B, Baltimore, MD 21287. email: kaisorn@jhmi.edu. 